NASCIMENTO, Luma Neto do. Dworking versus Waldron: os prós e os contras da revisão judicial. Revista Eletrônica Direito e Política, Programa de Pós-Graduação Stricto Sensu em Ciência Jurídica da UNIVALI, Itajaí, v.11, n.3, 30 quadrimestre de 2016. Disponível em: www.univali.br/direitoepolitica - ISSN 1980-7791

\title{
DWORKIN VERSUS WALDRON: OS PRÓS E OS CONTRAS DA REVISÃO JUDICIAL
}

DWORKING VERSUS WALDRON: PROS AND CONS OF JUDICIAL REVIEW

Luma Neto do Nascimento ${ }^{1}$

SUMÁRIO: Introdução; 1. A Evolução do Conceito de Democracia; 2. A revisão judicial para defensores do sistema majoritário ou do modelo consensual; 3 . Revisão Judicial: a defesa moral de Dworkin e a crítica de Waldron; Considerações finais; Referências das fontes citadas.

\section{RESUMO}

A ciência política tem avançado os seus questionamentos sobre os valores morais, princípios normativos e arranjos institucionais que seriam mais benéficos para um regime democrático. Entre esses arranjos, está a revisão constitucional. Neste trabalho será descrito os argumentos favoráveis e contrários à prática da revisão judicial, instrumento tão utilizado quanto questionado nas democracias atuais. Primeiramente, será descrita uma breve evolução sobre o conceito de democracia e o debate sobre o papel da revisão judicial em modelos institucionais democráticos. Logo após, será evidenciado o debate apontado na defesa da revisão judicial formulada nas obras de Ronald Dworkin e na respectiva crítica de Jeremy Waldron.

Palvras-Chave: Constituição; democracia; revisão judicial.

\section{ABSTRACT}

Political science has advanced its questioning of moral values, normative principles and institutional arrangements that would be more beneficial to democracy. Among these arrangements is the constitutional review. This work will be described the arguments for and against the practice of judicial review, as

\footnotetext{
1 Mestranda em Ciência Política pela Universidade Federal de Pernambuco. Bolsista FACEPE, Graduada em Ciência Política pela Universidade Federal de Pernambuco. E-mail: luma.neto@gmail.com
} 
NASCIMENTO, Luma Neto do. Dworking versus Waldron: os prós e os contras da revisão judicial. Revista Eletrônica Direito e Política, Programa de Pós-Graduação Stricto Sensu em Ciência Jurídica da UNIVALI, Itajaí, v.11, n.3, 30 quadrimestre de 2016. Disponível em: www.univali.br/direitoepolitica - ISSN 1980-7791

instrument used as questioned in the current democracies. First, a brief evolution of the concept of democracy and debate on the role of judicial review in democratic institutional models will be described. Soon after, it is evidenced the debate pointed out in defense of judicial review formulated in the works of Ronald Dworkin and their criticism of Jeremy Waldron.

Keywords: Constitution; democracy; judicial review.

\section{INTRODUÇÃO}

Como já afirmava Tocqueville ${ }^{2}$, a democracia deve ser o aspecto central no cenário político de uma sociedade, pois imprime a ela a ideia de igualdade de condições: a república democrática é caracterizada em sua concepção como o governo dos livres e iguais.

Assim, seria possível garantir igualdade moral e jurídica, dignidade e liberdade civil entre os cidadãos. Vale ressaltar, contudo, que apenas a existência da democracia em um Estado não significa garantir tais aspectos.

É necessário, ainda, que esta democracia, aliada a instituições eficientes, atendam preceitos constitucionais básicos e garantam alguns mecanismos efetivos de controles sociais para que se alcance uma democracia de qualidade. Nesse sentido, a qualidade de uma democracia está estreitamente ligada a aspectos que permitam o seu pleno funcionamento e a sua estabilidade.

A ideia de supremacia constitucional foi adotada na Constituição americana de 1787. Madison, um expoente federalista, ao tratar de modelos de reforma institucional reconhece que o poder político deve ser fragmentado para protegêlo da tirania tão tentadora aos humanos.

\footnotetext{
2 TOCQUEVILLE, Alexis de. A Democracia na América. Tradução de Francisco Weffort. São Paulo: Abril S. A. Cultural, 1985.
} 
NASCIMENTO, Luma Neto do. Dworking versus Waldron: os prós e os contras da revisão judicial. Revista Eletrônica Direito e Política, Programa de Pós-Graduação Stricto Sensu em Ciência Jurídica da UNIVALI, Itajaí, v.11, n.3, 30 quadrimestre de 2016. Disponível em: www.univali.br/direitoepolitica - ISSN 1980-7791

Uma frase célebre resume sua constatação: "se os homens fossem anjos, não seria necessário haver governos. Se os homens fossem governados por anjos, dispensar-se-iam os controles internos e externos" ${ }^{3}$.

A revisão judicial defendida pelos federalistas no seu papel sobre o sistema de freios e contrapesos agora é compartilhada entre vários países. As Constituições classificadas como democráticas e rígidas têm sido adotadas como catálogos de direitos fundamentais supremos e protegidos contra as maiorias parlamentares. O crescimento da importância dos Tribunais apresenta-se na resolução de questões políticas centrais ${ }^{4}$.

O principal objetivo do presente trabalho é descrever os principais argumentos favoráveis e contrários à revisão judicial na perspectiva de dois autores: Dworkin e Waldron.

Para tanto, pretende-se introduzir o tema tratando da evolução do conceito de democracia, evidenciando o porquê da literatura hoje incorporar a análise de dimensões que vão além da presença de eleições livres para definir o que seria uma democracia de qualidade.

Posteriormente, será mostrado o debate sobre o papel da revisão judicial na literatura que aborda os modelos institucionais de democracias, abordando os principais argumentos das obras de Lijphart, Ackerman e Melo, defensores do modelo consensual de democracia, e de Arato e Dahl, defensores do modelo majoritário

Finalmente, será evidenciado o debate sobre os valores morais e procedimentais na democracia, apontados com a ênfase na defesa da revisão judicial formulada nas obras de Ronald Dworkin e na respectiva crítica de Jeremy Waldron.

\footnotetext{
${ }^{3}$ MADISON, J. The federalist papers by Alexander Hamilton, James Madison and John Jay. Nova York, Bantam Books. 1982. p. 337.

4 BARBOZA, Estefânia Maria de Queiroz; KOZICKI, Katya. Judicialização da política e controle judicial de políticas públicas. Rev. direito GV vol.8 no.1 São Paulo jan./jun. 2012. P. 059-086.
} 
NASCIMENTO, Luma Neto do. Dworking versus Waldron: os prós e os contras da revisão judicial. Revista Eletrônica Direito e Política, Programa de Pós-Graduação Stricto Sensu em Ciência Jurídica da UNIVALI, Itajaí, v.11, n.3, 30 quadrimestre de 2016. Disponível em: www.univali.br/direitoepolitica - ISSN 1980-7791

\section{A EVOLUÇÃO DO CONCEITO DE DEMOCRACIA}

A concepção de democracia passou por diversos paradigmas na ciência política. Os seus valores já foram questionados a ponto de firmarem revoluções nos parâmetros de estudos democráticos. O bem comum já foi o objetivo fundamental da democracia e esta já foi reduzida a um método para se chegar ao poder político. Posteriormente, questões substanciais foram incorporadas ao conceito novamente e a complexidade das diferentes sociedades gerou uma necessidade para o estabelecimento de instituições políticas cada vez mais especializadas, como as Cortes Constitucionais e a revisão judicial.

As revoluções teóricas levaram a um questionamento sobre a qualidade do funcionamento das instituições democráticas. Entretanto, ainda há um extenso debate sobre quais modelos democráticos seriam benéficos ou maléficos levando em consideração determinados valores. Ao dar mais importância à responsabilização como um valor para a qualidade democrática, autores enfatizam a concentração de poder.

Para justificar uma partilha de poder entre diversas clivagens sociais, outros autores defendem instituições que permitam a participação de representantes de vários segmentos sociais no processo decisório.

Ao defender a democracia apenas como um procedimento para a chegada ao poder, autores deixam de lado a avaliação de questões substanciais. Enquanto que, aqueles que defendem a democracia como um valor em si mesma, levantam valores normativos.

Mas os critérios para uma democracia procedimental são condições necessárias para a existência de um regime considerado democrático. Schumpeter, em Capitalismo, Socialismo e Democracia, trouxe uma inovação na teoria democrática: a democracia seria um método, um procedimento ${ }^{5}$. O autor propôs

\footnotetext{
${ }^{5}$ SCHUMPETER, Joseph A. Capitalismo, Socialismo e Democracia. Tradução de Ruy Jungmann. Rio de Janeiro: Fundo de Cultura, 1961.
} 
NASCIMENTO, Luma Neto do. Dworking versus Waldron: os prós e os contras da revisão judicial. Revista Eletrônica Direito e Política, Programa de Pós-Graduação Stricto Sensu em Ciência Jurídica da UNIVALI, Itajaí, v.11, n.3, 30 quadrimestre de 2016. Disponível em: www.univali.br/direitoepolitica - ISSN 1980-7791

que um regime democrático se resumiria apenas em eleições, a qual seria a única forma do votante interferir no governo. Portanto, a importância da democracia estaria na competição eleitoral e o poder ficaria na mão das elites, ou seja, daqueles que, de acordo com o autor, estariam preparados para governar.

Para Schumpeter a democracia não é um tipo de sociedade, nem um conjunto de normas morais, mas um sistema em que o poder do eleitor resume-se em simplesmente sancionar ou não os nomes que lhe são oferecidos no mercado político, por meio de eleições competitivas ${ }^{6}$.

Adam Przeworski ${ }^{7}$ segue os passos de Schumpeter e desenvolve o conceito minimalista de democracia, o que seria o mais próximo do que conhecemos no senso comum: a democracia como sinônimo de eleições. O método democrático seria aquele que garantiria uma alternância no poder, através de eleições limpas que ocorreriam entre no mínimo dois e no máximo cinco anos de intervalo.

A garantia de que existem eleições limpas, livres e com um sistema multipartidário, garantiria a alternância no poder. Todas as outras indagações acerca da democracia, como violações das liberdades civis, por exemplo, seria uma discussão sobre a qualidade democrática.

Para fins de operacionalização, a concepção minimalista se mostraria em uma quase perfeição metodológica. Mas diante disso, fica fácil questionar: seriam as eleições condições suficientes para definir um país como democrático?

Dahl $^{8}$ foi um divisor de águas na teoria política contemporânea, ao adotar a concepção procedimental de Schumpeter, mas adicionando questões substanciais

\footnotetext{
6 GAMA NETO, Ricardo Borges. Minimalismo schumpeteriano, teoria econômica da democracia e escolha racional. Rev. Sociol. Polít., Curitiba, v. 19, n. 38, p. 27-42, fev. 2011.

7 PRZEWORSKI, Adam. Minimalist conception of democracy: a defense in Shapiro, Ian and Casiano Hacker-Cordón (eds.) Democracy's value. Cambridge: Cambridge University Press., pp. 21-55, 1999.
} 
NASCIMENTO, Luma Neto do. Dworking versus Waldron: os prós e os contras da revisão judicial. Revista Eletrônica Direito e Política, Programa de Pós-Graduação Stricto Sensu em Ciência Jurídica da UNIVALI, Itajaí, v.11, n.3, 30 quadrimestre de 2016. Disponível em: www.univali.br/direitoepolitica - ISSN 1980-7791

ao conceito democrático. Dahl aponta seis instituições de uma poliarquia (o mais próximo de um regime democrático): representantes eleitos; eleições livres, justas e frequentes; liberdade de expressão; fontes alternativas de informação; autonomia de associação; e cidadania inclusiva.

A partir de então, Dahl inspirou toda uma agenda de pesquisa em torno de valores normativos na democracia, que foram deixados de lado pela concepção minimalista.

Mainwaring e colaboradores $^{9}$ pensaram da mesma forma e o conceito minimalista de Przeworski foi reduzido a uma definição submínima. Os autores defendem que uma pequena dose de uma avaliação subjetiva é melhor do que não utilizar nenhum conhecimento profundo acerca dos regimes:

Por "subjetivos" não queremos dizer arbitrários, mas julgamentos fundados no conhecimento profundo dos casos e guiados por regras explícitas de codificação. Uma avaliação que se limite às eleições deixa de fora elementos essenciais para uma democracia, o que resulta numa definição submínima ${ }^{10}$.

Os autores então propõem uma classificação tricotômica da democracia, onde haveria regimes democráticos, semi-democráticos e autoritários. A metodologia de avaliação utilizada indica que quatro perguntas devem ser feitas para obter a classificação: 1) Existem eleições para o Legislativo e o Executivo?; 2) 0 direito de voto é inclusivo?; 3) As liberdades civis são respeitadas?; 4) As autoridades eleitas têm reais condições de exercer o governo?

Se a resposta para todas as perguntas for "sim", o regime em avaliação é considerado "democrático". Entretanto, se houver uma violação parcial em pelo menos um dos quatro aspectos citados, o regime é considerado "semi-

\footnotetext{
8 DAHL, Robert. Um prefácio à teoria democrática. Tradução de Ruy Jungmann. Rio de Janeiro: Zahar, 1989.
}

9 MAINWARING, Scott; BRINKS, Daniel; e PÉREZ-LIÑÁN, Aníbal. Classificando Regimes

Políticos na América Latina in Dados, vol. 44, no. 4, 2001. pp. 645-687.

10 MAINWARING, Scott; BRINKS, Daniel; e PÉREZ-LIÑÁN, Aníbal. Classificando Regimes

Políticos na América Latina. p. 646. 
NASCIMENTO, Luma Neto do. Dworking versus Waldron: os prós e os contras da revisão judicial. Revista Eletrônica Direito e Política, Programa de Pós-Graduação Stricto Sensu em Ciência Jurídica da UNIVALI, Itajaí, v.11, n.3, 30 quadrimestre de 2016. Disponível em: www.univali.br/direitoepolitica - ISSN 1980-7791

democrático". Seguindo a mesma lógica, se houver pelo menos uma violação grave de um dos critérios, o país é considerado "autoritário".

Daí então já se observa um avanço no debate sobre a democracia. Aos poucos o conceito subminimalista vai perdendo a sua força. Além dos primeiros requisitos, procedimentais, que se resumem em eleições inclusivas, os autores incluem duas dimensões substanciais.

A democracia também deve incluir as liberdades civis, pois em países onde há eleições os direitos dos cidadãos podem ser frequentemente violados com pouca perspectiva de punição, e o controle civil sobre os militares também é essencial para verificar se quem é eleito de fato tem autonomia para governar, já que as instituições coercitivas ou forças paramilitares seriam capazes de limitar as decisões dos governantes.

Portanto, diversas questões normativas foram incorporadas aos estudos democráticos. Questões econômicas, tratando de igualdade social, desenvolvimento humano e estado de direito, entraram para o debate normativo sobre a democracia, muitas vezes retomando argumentos de autores clássicos.

Guillermo O'Donnell ${ }^{11}$, um expoente nos estudos democráticos na América Latina, é um exemplo de autor que defende um valor normativo na democracia: um forte estado de direito. Um verdadeiro estado democrático de direito seria aquele com um Poder Judiciário independente, com uma justiça que alcance a todos os cidadãos através de processos que corram em um tempo razoável. Até então, nada de contrariante.

Contudo, o autor argentino defende a existência de uma instituição que gera bastantes controvérsias entre os teóricos da democracia: a existência de uma corte constitucional e consequentemente, a revisão judicial.

${ }^{11}$ O'DONNELL, Guillermo. "Why the rule of law matters" in Diamond, Larry and Leonardo Morlino (eds.). Assessing the Quality of Democracy. Baltimore: The Johns Hopkins University Press, 2005. pp 3-17. 
NASCIMENTO, Luma Neto do. Dworking versus Waldron: os prós e os contras da revisão judicial. Revista Eletrônica Direito e Política, Programa de Pós-Graduação Stricto Sensu em Ciência Jurídica da UNIVALI, Itajaí, v.11, n.3, 30 quadrimestre de 2016. Disponível em: www.univali.br/direitoepolitica - ISSN 1980-7791

Portanto, a concepção minimalista mostrou ser uma condição necessária, porém não suficiente para resumir o debate sobre a democracia. A ciência política tem avançado os seus questionamentos sobre os valores morais, princípios normativos e arranjos institucionais que seriam mais benéficos para um regime democrático. Entre esses arranjos, está a revisão constitucional.

\section{A REVISÃo JUDICIAL PARA DEFENSORES DO SISTEMA MAJORITÁRIO OU DO MODELO CONSENSUAL}

O estudo aprofundado de mecanismos institucionais para um bom funcionamento democrático ainda é muito superficial nas definições minimalistas da democracia apontadas por Schumpeter e Przeworski. Na realidade, existem muitas maneiras de organização e funcionamento da democracia, com uma grande variedade de instituições governamentais formais, além de um amplo debate a respeito do assunto.

Lijphart $^{12}$, em seu trabalho sobre modelos institucionais democráticos, aponta dois tipos básicos de regime democrático: o modelo majoritário e o modelo consensual de democracia.

No modelo majoritário, o poder político fica nas mãos de uma pequena maioria, já o modelo consensual tenta compartilhar, dispersar e limitar o poder de várias maneiras. Portanto, o modelo majoritário de democracia é exclusivo e competitivo, tendo como um exemplo quase perfeito, a democracia parlamentarista britânica.

Já o modelo o consensual se caracteriza pela negociação e a concessão, e a Suíça seria um bom exemplo dessa espécie de democracia. Entre as instituições que caracterizam um modelo majoritário estariam um governo centralizado, unitário, unicameral e constituições flexíveis, enquanto que um modelo

12 LIJPHART, Arend. Modelos de democracia: desempenho e padrões de governo em 36 países. Rio de Janeiro, Ed. Civilização Brasileira, 2003. 
NASCIMENTO, Luma Neto do. Dworking versus Waldron: os prós e os contras da revisão judicial. Revista Eletrônica Direito e Política, Programa de Pós-Graduação Stricto Sensu em Ciência Jurídica da UNIVALI, Itajaí, v.11, n.3, 30 quadrimestre de 2016. Disponível em: www.univali.br/direitoepolitica - ISSN 1980-7791

consensual possuiria um governo descentralizado, federalista, bicameral e uma constituição rígida e um consequente sistema de revisão judicial.

Diversos autores na ciência política contemporânea passaram então a escolher a qual lado defender: se a democracia funcionaria melhor em um arcabouço institucional guiado por regras majoritárias ou por regras consensuais. Entretanto, existe uma tendência para que os autores na política comparada defendam os princípios majoritários, principalmente com o objetivo de colocar em primeiro plano a importância de se garantir mecanismos que facilitem a accountability, ou seja, a responsabilização das ações dos agentes estatais ${ }^{13}$.

Um exemplo dessa defesa de princípios majoritários para favorecer os meios de gerar a accountability está em Representação, Soberania e Accountability de Andrew Arato $^{14}$. O autor defende que instituições que centralizam o poder facilitam a accountability, colocando a responsabilização no centro da análise de uma qualidade democrática.

A separação de poderes, o bicameralismo, a revisão judicial e o federalismo representam o compromisso da democracia madsoniana de defender os direitos das minorias perante as maiorias. Entretanto, Arato desconfia da real eficácia das instituições consensuais, como o forte constitucionalismo e a revisão judicial ${ }^{15}$.

A revisão judicial é, portanto, um atributo essencial em desenhos constitucionais consensuais. Contudo, existe um paradoxo: quanto mais fragmentado o poder, menor a capacidade de responsabilização. Portanto, os modelos constitucionais que reforçam a accountability não seriam compatíveis com a revisão judicial.

\footnotetext{
13 MELO, Marcus. O viés majoritário na política comparada: responsabilização, desenho institucional e qualidade da democracia. Revista Brasileira de Ciências Sociais, vol. 22, n. 63, fevereiro de 2007. p. 11 a 29.

${ }^{14}$ ARATO, Andrew. Representação, soberania popular, e accountability. Tradução de Heloísa B. de Almeida. Lua Nova, n. 55-56, 2002. p. 85 a 103.

${ }^{15}$ ARATO, Andrew. Representação, soberania popular, e accountability. p. 88.
} 
NASCIMENTO, Luma Neto do. Dworking versus Waldron: os prós e os contras da revisão judicial. Revista Eletrônica Direito e Política, Programa de Pós-Graduação Stricto Sensu em Ciência Jurídica da UNIVALI, Itajaí, v.11, n.3, 30 quadrimestre de 2016. Disponível em: www.univali.br/direitoepolitica - ISSN 1980-7791

Os juízes teriam menos credenciais democráticas para resolver supostas injustiças cometidas pelo legislativo. A única diferença para os cidadãos estaria em apelar para uma aristocracia judiciária, em vez de uma aristocracia legislativa. Mas Arato não está sozinho no argumento da menor legitimidade da revisão judicial, em relação às credenciais democráticas do legislativo. Jeremy Waldron critica especialmente a revisão judicial de decisões legislativas sobre discordâncias a respeito de direitos ${ }^{16}$. Em seu conjunto de argumentos contra o controle constitucional dessa espécie, o autor afirma, assim como Arato, que o poder legislativo possui uma legitimidade democrática mais forte que a dos juízes e por esse e outros motivos, essas divergências não deveriam ter como árbitro final os juízes de uma corte suprema.

Melo ${ }^{17}$ tece suas criticas ao viés majoritário da política comparada, principalmente no típico argumento proposto por Arato. A política comparada coloca a accountability no núcleo da análise democrática, onde quanto menos atores com poder de veto estejam presentes numa democracia, melhor a qualidade da responsabilização.

Entretanto, existe uma tendência nas democracias avançadas em aumentar o escopo de poder do Judiciário, utilizando juízes como árbitros para a proteção de direitos normativos, diante da crescente complexidade das sociedades ao redor do mundo. A política comparada estaria, portanto, se distanciando do desenho institucional que é uma tendência nas democracias contemporâneas.

A defesa do modelo consensual está presente nas avaliações democráticas de Lijphart $^{18}$. O autor defende instituições consensuais como o federalismo, mas principalmente uma combinação de parlamentarismo e representação proporcional. O autor conclui que diante de sociedades complexas, uma

\footnotetext{
${ }^{16}$ WALDRON, Jeremy. The core of the case against judicial review, Yale Law Journal, n. 115, 2006. pp. 1346 a 1406.

17 MELO, Marcus. O viés majoritário na política comparada: responsabilização, desenho institucional e qualidade da democracia. p. 13.

18 LIJPHART, Arendt. Constitutional choices for new democracies. Journal of Democracy, vol. 2, n. 1, winter 1991. p. 72 a 84.
} 
NASCIMENTO, Luma Neto do. Dworking versus Waldron: os prós e os contras da revisão judicial. Revista Eletrônica Direito e Política, Programa de Pós-Graduação Stricto Sensu em Ciência Jurídica da UNIVALI, Itajaí, v.11, n.3, 30 quadrimestre de 2016. Disponível em: www.univali.br/direitoepolitica - ISSN 1980-7791

convivência pacífica só é possível com a inclusão de minorias no processo decisório ${ }^{19}$.

Como aponta Marcus Andre Melo, as democracias contemporâneas estão cada vez mais heterogêneas, mas as defesas majoritárias pressupõem sociedades homogêneas ${ }^{20}$. Lijphart então propõe um conjunto de prerrogativas institucionais para sociedades com profundas clivagens de diversos tipos ${ }^{21}$. Esses diferentes segmentos sociais só poderiam conviver pacificamente diante de uma partilha do poder. Portanto, o parlamentarismo, com a composição de um gabinete e um sistema de representação proporcional aumentariam as chances das minorias estarem representadas no poder central ${ }^{22}$.

Lijphart sugere outros elementos desse arranjo institucional, como um sistema com distritos menores, que favoreceria uma maior homogeneidade dentro desses distritos. O que retifica a defesa de uma maior descentralização e divisão do poder, para que cidadãos de diversas clivagens possam estar representados e protegidos dos desejos da maioria ${ }^{23}$.

Bruce Ackerman ${ }^{24}$ por sua vez, retoma alguns argumentos de Lijphart. O autor defende um Parlamentarismo Limitado, onde estão presentes instituições consensuais como o federalismo e o bicameralismo, assim como defende

\footnotetext{
19 LIJPHART, Arendt. Constitutional choices for new democracies. p. 83.

20 MELO, Marcus. O viés majoritário na política comparada: responsabilização, desenho institucional e qualidade da democracia. p. 13.

21 LIJPHART, Arendt. Constitutional design for divided societies. In: Thinking about Democracy: power sharing and majority rule in theory and practice. London and NY: Routledge, 2008. p. 75 a 88.

22 LIJPHART, Arendt. Constitutional design for divided societies. p. 80 a 84 .

${ }^{23}$ LIJPHART, Arendt. Constitutional design for divided societies. p. 84

${ }^{24}$ ACKERMAN, Bruce. The new separation of powers. Harvard Law Review, vol. 113, n.3. 2000. p. 634 a 725 .
} 
NASCIMENTO, Luma Neto do. Dworking versus Waldron: os prós e os contras da revisão judicial. Revista Eletrônica Direito e Política, Programa de Pós-Graduação Stricto Sensu em Ciência Jurídica da UNIVALI, Itajaí, v.11, n.3, 30 quadrimestre de 2016. Disponível em: www.univali.br/direitoepolitica - ISSN 1980-7791

Lijphart. Entretanto, Ackerman propõe um bicameralismo assimétrico, com um Senado com um menor poder decisório ${ }^{25}$.

Lijphart e Ackerman ainda discordam quanto ao papel dos referendos. Lijphart prefere que os referendos sejam evitados, para que não haja uma imposição da vontade da maioria sobre as minorias ${ }^{26}$. Determinados assuntos deveriam, portanto, ser decididos em assembleia, com a participação de representantes das diversas minorias e da maioria populacional. Já Ackerman pretende limitar o poder do Parlamento através da participação popular, que seria expressa por referendos sequenciais.

Para Ackerman, o sistema parlamentar reduz o número de ataques ao Estado de Direito, mas por outro lado, a revisão judicial também cumpriria esse papel. Por este motivo, o autor inclui a revisão judicial no seu modelo de Parlamentarismo Limitado. Ackerman defende uma maior limitação ao poder do Parlamento, através da presença de uma Constituição escrita e de uma Corte Constitucional para promover um controle do poder, além de outras instituições com o propósito de frear a força do Parlamento.

A Corte Constitucional seria necessária para o controle da supremacia constitucional, pois Ackerman acredita que se não houver esse tipo de controle, os princípios presentes na Constituição não serão observados pela maioria parlamentar ou pelo próprio plebiscito ${ }^{27}$.

A despeito das questões normativas apontadas em sua obra, Dahl é um autor que sai em defesa do princípio majoritário, já que as alternativas ao domínio da maioria também seriam bastante problemáticas ${ }^{28}$. Em outras palavras, mesmo que o domínio da maioria seja ruim, pior é estar sem ele. Nenhuma outra regra

\footnotetext{
${ }^{25}$ ACKERMAN, Bruce. The new separation of powers. p. 681 a 685.

${ }^{26}$ LIJPHART, Arendt Constitutional design for divided societies. p. 85

${ }^{27}$ ACKERMAN, Bruce. The new separation of powers. 2000. p. 663 a 670 .

${ }^{28}$ DAHL, Robert. A democracia e seus críticos. Tradução de Patrícia F. Ribeiro. São Paulo: WMF Martins Fontes, 2012.
} 
NASCIMENTO, Luma Neto do. Dworking versus Waldron: os prós e os contras da revisão judicial. Revista Eletrônica Direito e Política, Programa de Pós-Graduação Stricto Sensu em Ciência Jurídica da UNIVALI, Itajaí, v.11, n.3, 30 quadrimestre de 2016. Disponível em: www.univali.br/direitoepolitica - ISSN 1980-7791

poderia ser um melhor substituto para o método da maioria. Portanto, não existiria uma solução universal para o problema da proteção de direitos. As soluções dependeriam da cultura política, de experiências históricas e das instituições de cada país, que seriam discutidas na esfera pública, entre legisladores eleitos. A justiça seria uma consequência do processo democrático, e não algo imposto externamente.

Como visto, os desenhos institucionais majoritários e consensuais são modelos democráticos, mas que diferem em alguns aspectos sobre a divisão ou concentração de poder. Alguns autores saem em defesa especificamente do valor consensual da revisão judicial, enquanto que outros se mantiveram na defesa no princípio majoritário, onde não há revisão constitucional por parte de juízes em uma suprema corte. Mas ainda existem outros valores que entram nos trade offs sobre o desempenho democrático. A revisão judicial é analisada especificamente por alguns autores, um debate que vai além do seu caráter institucional.

\section{REVISÃo JUdICIAL: A DEFESA MORAL DE DWORKIN E A CRÍtICA DE WALDRON}

Nesta seção tratarei sobre dois autores que tecem teorias especialmente voltadas para a revisão judicial. Como demonstrado anteriormente, o tema das revisões constitucionais tem como base o debate institucional entre o princípio majoritário e o consensual.

A revisão judicial faz parte das instituições proporcionais, que permitem uma maior dispersão do poder. O mecanismo consensual é criticado pelos defensores dos princípios majoritários, pois estes defendem uma maior concentração do poder, o que favoreceria os mecanismos de accountability.

Mas outras questões também são indagadas acerca dos princípios morais que acarretam uma revisão judicial. Para os defensores do princípio majoritário, o método da maioria já é um valor moral em si mesmo: desde que o procedimento seja pela decisão da maioria, o "povo" estaria sendo regido de forma justa. Já 
NASCIMENTO, Luma Neto do. Dworking versus Waldron: os prós e os contras da revisão judicial. Revista Eletrônica Direito e Política, Programa de Pós-Graduação Stricto Sensu em Ciência Jurídica da UNIVALI, Itajaí, v.11, n.3, 30 quadrimestre de 2016. Disponível em: www.univali.br/direitoepolitica - ISSN 1980-7791

para os teóricos do modelo consensual, o "indivíduo" deve estar protegido de uma tirania da maioria e a constituição de um país deveria assegurar o cumprimento dos valores democráticos.

Ronald Dworkin é um defensor da concepção constitucional da democracia: assume que a Constituição de um país seria uma espécie de guardiã dos princípios morais, e estes deveriam ser aplicados por juízes ${ }^{29}$. Esses membros do Poder Judiciário, já aplicariam esses valores morais nos julgamentos em seu cotidiano de trabalho.

Em contraste, Jeremy Waldron, um adepto do princípio majoritário, defende com unhas e dentes o método da maioria, assim como Dahl. Para Waldron, o procedimento majoritário, mesmo que às vezes possa gerar injustiças, ainda é o único método benéfico para a democracia ${ }^{30}$. Dworkin e Waldron serão os dois autores de opiniões antagônicas que terão seus argumentos brevemente elencados.

Robert Dahl já havia questionado em 1957 a Suprema Corte norte-americana, em seu artigo Decision-making in a democracy: the Supreme Court as a national policy maker ${ }^{31}$. Para este autor, o suposto papel da Suprema Corte em estar de acordo com as preferências de uma minoria de cidadãos e contra as preferências de uma maioria, é incompatível com a democracia, pois isto iria contra o princípio majoritário, que para o autor é um valor democrático fundamental. Além disso, não seria possível estabelecer com certeza se uma determinada decisão foi apoiada por uma minoria ou por uma maioria dos cidadãos.

Como consequência de poderes constitucionais a ela atribuídos, a Suprema Corte norte-americana expandiu a sua atuação para o âmbito político, tomando decisões sobre temas polêmicos na política nacional, o que seria o motivo

\footnotetext{
29 DWORKIN, Ronald. A leitura moral e a premissa majoritária. In: O Direito da Liberdade: a leitura moral da Constituição norte-americana. Tradução de Marcelo B. Cipolla. São Paulo: Martins Fontes, 2006. p.4.

${ }^{30}$ WALDRON, Jeremy. The core of the case against judicial review. p. 1406.

$31 \mathrm{DAHL}$, Robert A. Decision-making in a democracy: the Supreme Court as a national policy-maker. The Journal of Public Law, n. 6, 1957. p. 279 a 295.
} 
NASCIMENTO, Luma Neto do. Dworking versus Waldron: os prós e os contras da revisão judicial. Revista Eletrônica Direito e Política, Programa de Pós-Graduação Stricto Sensu em Ciência Jurídica da UNIVALI, Itajaí, v.11, n.3, 30 quadrimestre de 2016. Disponível em: www.univali.br/direitoepolitica - ISSN 1980-7791

principal para a crítica de Robert Dahl sobre a existência dessa instituição em um modelo democrático.

Waldron, em sua obra The Core of the Case Against Judicial Review, segue os passos de Dahl na sua desconfiança na capacidade de julgamento dos juízes. Estes não possuiriam legitimidade democrática da mesma forma que os legisladores, para impor a justiça na esfera pública de deliberação. Waldron critica uma suposta pregação de que a revisão judicial seria um valor normativo obrigatório nas democracias contemporâneas. A revisão judicial não seria, para o autor, um sinônimo de proteção a direitos fundamentais ${ }^{32}$.

Já Dworkin é um expresso defensor da leitura moral, definida pelo autor como um método particular de ler e executar uma constituição política ${ }^{33}$. Portanto, ao contrário de Waldron, Dworkin é um defensor do constitucionalismo e usa a Constituição como uma fonte de princípios democráticos que devem ser observados pelos juízes.

Logo, a leitura moral não ficaria a critério de um juiz, já que ele deve fundamentar as suas decisões baseando-se nos princípios da Declaração de Direitos, e esses princípios garantiriam que uma lei seria de fato de caráter democrático.

Mas na opinião de Waldron, as palavras utilizadas na Declaração de Direitos não foram escolhidas na intenção de resolver discordâncias sobre direitos, e se foram, elas foram escolhidas para resolver discordâncias que ocorreram na época em que a Constituição foi redigida. O autor também faz uma crítica ao rígido formalismo textual da Declaração de Direitos, o que poderia gerar uma orientação obsessiva para os seus fundamentos ${ }^{34}$.

\footnotetext{
32 WALDRON, Jeremy. The core of the case against judicial review. p. $1363-1366$.

${ }^{33}$ DWORKIN, Ronald. A leitura moral e a premissa majoritária. p.2.

${ }^{34}$ WALDRON, Jeremy. The core of the case against judicial review. p. $1366-1369$.
} 
NASCIMENTO, Luma Neto do. Dworking versus Waldron: os prós e os contras da revisão judicial. Revista Eletrônica Direito e Política, Programa de Pós-Graduação Stricto Sensu em Ciência Jurídica da UNIVALI, Itajaí, v.11, n.3, 30 quadrimestre de 2016. Disponível em: www.univali.br/direitoepolitica - ISSN 1980-7791

Dworkin $^{35}$ avançou em uma teoria descritiva do sistema legal americano, afirmando que sua teoria envolve um contraexemplo para as teorias do positivismo jurídico em geral, e para a do Professor Hart $^{36}$, em particular.

A principal diferença entre as abordagens de Hart e Dworkin está na divisão entre direito e moral. Hart é favorável à separação entre direito e moral, e afirma que sua teoria descritiva pode aceitar a presença de princípios que podem ser invocados pelo juiz no momento da decisão. Entretanto, Hart refuta a possibilidade de valores morais vinculantes ou de que os juízes tenham uma obrigação jurídica de julgar um caso de uma determinada forma, a fim de se chegar a uma resposta correta, como defende Dworkin.

Dworkin, por sua vez, condena a posição positivista de que direito e moral estão separados. O autor afirma que a sua teoria fornece uma interpretação normativa do direito, preferível à abordagem fornecida pelo positivismo. Portanto, o direito deve ser interpretado de forma construtiva, através do apoio institucional conferido a determinados princípios, da busca do histórico de decisões passadas e se elas são compatíveis com os princípios morais da comunidade no momento do julgamento, a fim de justificar a utilização da coerção estatal.

Dworkin, portanto, defende que a leitura moral propõe uma interpretação que faz referência a princípios morais e de justiça. O defensor da revisão judicial afirma que no seu trabalho cotidiano, os juízes aplicam as exigências morais da Constituição em casos concretos. Segundo o autor, o ideal da democracia americana é um governo baseado em princípios e esse raciocínio tem sido reproduzido ao redor do mundo ${ }^{37}$.

Entretanto, Waldron não acredita que os juízes tenham uma preocupação moral: os juízes estariam mais preocupados com a legitimidade de um processo que Ihes permitem decidir questões de divergências de direitos, por isso se apegam

35 DWORKIN, The Model of Rules, 35 U. CHI. L. REV. 14, 1967;

${ }^{36}$ HART, Herbert L.A. O Conceito de Direito. 4 ed. Tradução de A. Ribeiro Mendes. Lisboa: Fundação Caloustre Gulbenkian, 2005.

${ }^{37}$ DWORKIN, Ronald. A leitura moral e a premissa majoritária. p.9. 
NASCIMENTO, Luma Neto do. Dworking versus Waldron: os prós e os contras da revisão judicial. Revista Eletrônica Direito e Política, Programa de Pós-Graduação Stricto Sensu em Ciência Jurídica da UNIVALI, Itajaí, v.11, n.3, 30 quadrimestre de 2016. Disponível em: www.univali.br/direitoepolitica - ISSN 1980-7791

aos textos que autorizam a sua interpretação, em vez de discutir razões morais diretamente ${ }^{38}$. Para Dahl, existe uma alta convergência das decisões da Suprema Corte americana com as decisões das maiorias legislativas ${ }^{39}$.

Portanto, essa defesa das minorias que a revisão judicial deveria resguardar pouco é feita na realidade, já que metade das sentenças da Suprema Corte norte-americana foram proferidas mais de quatro anos depois que a legislação foi aprovada na legislatura.

As linhas de interpretação dos princípios constitucionais devem seguir uma linha seguida por outros juízes no passado, de acordo com Dworkin ${ }^{40}$. Esse direcionamento para a análise de precedentes jurídicos é bastante criticada por Waldron. Segundo este autor, a maioria das justificativas impostas pela Suprema Corte norte-americana tratavam apenas de casos passados que obtiveram as mesmas decisões ou falavam sobre dispositivos legais que davam cabimento às suas interpretações.

O discurso moral, tão indagado por Dworkin, na verdade era pouco explorado. A Constituição não seria vista pelos juízes como uma fonte de princípios morais, mas apenas como uma fonte de justificativas para as suas decisões ${ }^{41}$.

O princípio majoritário é rejeitado por Dworkin. Ao contrário do valor fundamental defendido pelo princípio majoritário, onde os procedimentos políticos devem ser direcionados para a meta de atingir a maioria dos cidadãos, para o defensor da revisão judicial o objetivo fundamental da democracia é que:

Decisões coletivas sejam tomadas por instituições políticas, cuja estrutura, composição e modo de operação dediquem a

\footnotetext{
${ }^{38}$ WALDRON, Jeremy. The core of the case against judicial review. p. 1376.

$39 \mathrm{DAHL}$, Robert A. Decision-making in a democracy: the Supreme Court as a national policy-maker. P. 285.

40 DWORKIN, Ronald. A leitura moral e a premissa majoritária. p.15.

${ }^{41}$ WALDRON, Jeremy. The core of the case against judicial review. pp. 1383.
} 
NASCIMENTO, Luma Neto do. Dworking versus Waldron: os prós e os contras da revisão judicial. Revista Eletrônica Direito e Política, Programa de Pós-Graduação Stricto Sensu em Ciência Jurídica da UNIVALI, Itajaí, v.11, n.3, 30 quadrimestre de 2016. Disponível em: www.univali.br/direitoepolitica - ISSN 1980-7791

todos os membros da comunidade, enquanto indivíduos, a mesma consideração e o mesmo respeito político ${ }^{42}$.

Dahl e Waldron são defensores do procedimento: mesmo que alguma decisão da maioria seja controversa, pior seria se os juízes de uma Suprema Corte tomassem uma decisão diferente da maioria, mesmo que, moralmente, fosse mais correta.

Portanto, os fins não justificam os meios para os defensores do princípio majoritário: as decisões devem ser pelo princípio da maioria, mesmo que haja riscos de injustiça. Para Waldron, as Cortes não estão livres de tomarem decisões injustas, assim como os políticos. Em outras palavras, já que, teoricamente, há um risco de se cometer injustiça de todo jeito, melhor que seja cometida pelo método da maioria.

A ideia de tirania da maioria estabelecida na teoria política é refutada por Waldron. Uma simples divergência de direitos não significaria que houve uma injustiça. A tirania da maioria ocorreria quando os direitos ou interesses de uma minoria são erradamente subordinados aos da maioria. Por exemplo, se uma maioria parlamentar de legisladores brancos aprovassem leis que criasse privilégios para os brancos, os legisladores negros estariam sofrendo com uma tirania ${ }^{43}$.

Mas o contraste é: enquanto os majoritários acreditam que uma decisão é democrática apenas se esta é um resultado de um procedimento de decisão pela maioria, os defensores da revisão judicial acreditam que a substância da lei deve ser democrática em si mesma.

Dworkin, por exemplo, afirma que quando as instituições majoritárias garantem as condições democráticas, as suas respectivas decisões devem ser aceitas. Mas

42 DWORKIN, Ronald. A leitura moral e a premissa majoritária. p.26.

${ }^{43}$ WALDRON, Jeremy. The core of the case against judicial review. pp. $1395-1401$ 
NASCIMENTO, Luma Neto do. Dworking versus Waldron: os prós e os contras da revisão judicial. Revista Eletrônica Direito e Política, Programa de Pós-Graduação Stricto Sensu em Ciência Jurídica da UNIVALI, Itajaí, v.11, n.3, 30 quadrimestre de 2016. Disponível em: www.univali.br/direitoepolitica - ISSN 1980-7791

quando essas condições não são respeitadas, outros procedimentos, que não os majoritários, serão necessários para garantir os valores democráticos ${ }^{44}$.

Entretanto, Dworkin ${ }^{45}$ estabelece uma limitação na ação das Cortes. Em "A Virtude Soberana: a teoria e a prática da igualdade" o autor ressalva que não seriam todas as decisões finais que caberiam aos juízes, mas apenas aquelas que se tratassem de questões insensíveis à escolha. As questões insensíveis à escolha seriam aquelas cujas decisões não dependessem de quantas pessoas querem ou aprovam a medida. Fica mais claro o entendimento do conceito quando se compara com a definição das questões sensíveis à escolha, já que estas seriam aquelas onde a mera distribuição de preferências seria suficiente, ou seja, é possível medir quantos cidadãos seriam beneficiados pela nova lei.

Dworkin é um defensor da democracia no nível do indivíduo, e ele próprio admite que o seu livro apresenta uma "visão liberal da Constituição norte-americana" ${ }^{46}$. Portanto, o autor está preocupado com determinadas liberdades, proteções e garantias individuais, que deveriam ser protegidas por uma Constituição e por um sistema de revisão judicial. As questões insensíveis à escolha, portanto, não deveriam estar nas mãos da maioria, pois existiriam fatores nessas questões que podem tolher valores ou liberdades individuais.

Mas essa suposta injustiça a nível individual é relativa para Waldron. O autor consegue exemplificar seu argumento através do debate sobre o aborto. Para aqueles que o defendem, a criminalização do aborto tolhe as liberdades das mulheres, alegando uma tirania da maioria. Já os contrários à ação afirmam que o aborto fere o direito à vida do feto - considerando este também como um indivíduo -, portanto haveria uma tirania para a futura criança. Temos ai os frutos de uma árvore envenenada: mesmo que o resultado seja mais ético por

\footnotetext{
${ }^{44}$ DWORKIN, Ronald [1996] A leitura moral e a premissa majoritária. p.26 - 27.

45 DWORKIN, Ronald [2000] A Virtude Soberana: a teoria e a prática da igualdade. Tradução de Jussara Simões. São Paulo: WMF Martins Fontes, 2013. p. 282.

${ }^{46}$ DWORKIN, Ronald [1996] A leitura moral e a premissa majoritária. p.58
} 
NASCIMENTO, Luma Neto do. Dworking versus Waldron: os prós e os contras da revisão judicial. Revista Eletrônica Direito e Política, Programa de Pós-Graduação Stricto Sensu em Ciência Jurídica da UNIVALI, Itajaí, v.11, n.3, 30 quadrimestre de 2016. Disponível em: www.univali.br/direitoepolitica - ISSN 1980-7791

alguma perspectiva, se ele não foi alcançado através de um procedimento majoritário, ele é injusto.

Outro debate acerca da revisão judicial está na legitimidade dos juízes de uma suprema corte para serem os árbitros finais de uma decisão de controvérsia sobre direitos. Waldron, mesmo sendo um crítico da revisão judicial, concorda com Dworkin no sentido de que os juízes têm uma legitimidade democrática, já que são indicados pelo presidente e confirmados pelo senado. Contudo, Waldron fala em uma legitimidade comparativa: os legisladores teriam mais credenciais democráticas que os juízes para decidir as questões de divergências de direitos ou na nomenclatura de Dworkin, as questões insensíveis à escolha ${ }^{47}$.

Vale ressaltar que Waldron estabelece condições estruturais para que haja uma negação à revisão judicial: 1) instituições democráticas trabalhando razoavelmente bem; 2) um conjunto de instituições judiciais em razoável funcionamento; 3) comprometimento da maioria da sociedade à ideia de direitos individuais e de minoria; e 4) discordâncias substanciais de boa fé a respeito dos direitos ${ }^{48}$. Mas o autor admite que a sua teoria não tenha sustentação diante da ausência de um desses pressupostos.

Porém, também não é possível afirmar, segundo o autor, que a revisão judicial seria uma forma alternativa para resolver o problema. Por este motivo, Waldron sugere uma nova agenda de pesquisa, para que possam ser discutidos novos procedimentos para decidir divergências sobre direitos ${ }^{49}$.

Portanto, Dworkin e Waldron concordam que existem divergências em um regime democrático que geram discussões profundas acerca das liberdades individuais e de outros valores éticos e morais nas diferentes sociedades contemporâneas. Entretanto, os dois divergem quanto ao procedimento e ao conteúdo da democracia. Para Waldron, o valor está no método de decisão, já

\footnotetext{
${ }^{47}$ WALDRON, Jeremy. The core of the case against judicial review. p. 1391.

48 WALDRON, Jeremy. The core of the case against judicial review. pp. 1359-1369.

${ }^{49}$ WALDRON, Jeremy. The core of the case against judicial review. p. 1406.
} 
NASCIMENTO, Luma Neto do. Dworking versus Waldron: os prós e os contras da revisão judicial. Revista Eletrônica Direito e Política, Programa de Pós-Graduação Stricto Sensu em Ciência Jurídica da UNIVALI, Itajaí, v.11, n.3, 30 quadrimestre de 2016. Disponível em: www.univali.br/direitoepolitica - ISSN 1980-7791

para Dworkin, uma lei deve conter valores democráticos em si mesma, valores estes determinados previamente por uma Constituição escrita e resguardados por um sistema de revisão constitucional.

\section{CONSIDERAÇÕES FINAIS}

Este trabalho buscou mostrar um panorama teórico acerca da revisão judicial. Foi evidenciado como este mecanismo institucional entrou para a discussão dos valores democráticos, mostrando uma breve evolução do conceito de democracia.

Também foi elencado o debate sobre os modelos institucionais democráticos e onde a revisão judicial se encaixaria, ressaltando os argumentos dos defensores de cada modelo institucional para a inclusão ou exclusão da revisão judicial.

Por fim, foi descrito o debate entre Jeremy Waldron e Ronald Dworkin, dois autores que dedicam trabalhos voltados especialmente para a discussão de valores e princípios democráticos que estariam ausentes ou presentes em um sistema que incluísse a revisão judicial.

Concluiu-se que a revisão constitucional encontra-se como um componente do arcabouço institucional consensual, apesar de haver uma tendência inclusive em sistemas majoritários em utilizar esse mecanismo ${ }^{50}$.

Para os defensores da democracia consensual, a revisão judicial representa a partilha do poder entre as minorias e maiorias, através de um controle externo: os juízes das supremas cortes. Enquanto que para o mainstream da política comparada, com a revisão judicial vem um déficit na capacidade de responsabilização e um detrimento do poder legislativo. Mesmo diante das complexidades e divergências nas diferentes sociedades, os legisladores, eleitos

50 MELO, Marcus. O viés majoritário na política comparada: responsabilização, desenho institucional e qualidade da democracia. p.13. 
NASCIMENTO, Luma Neto do. Dworking versus Waldron: os prós e os contras da revisão judicial. Revista Eletrônica Direito e Política, Programa de Pós-Graduação Stricto Sensu em Ciência Jurídica da UNIVALI, Itajaí, v.11, n.3, 30 quadrimestre de 2016. Disponível em: www.univali.br/direitoepolitica - ISSN 1980-7791

democraticamente, seriam os mais aptos a formular e validar as leis que regem uma sociedade.

Como disse Dworkin ${ }^{51}$, é necessário fazer um exame dos valores mais profundos que estão por trás do conceito de democracia, para que haja uma defesa do princípio majoritário ou do modelo consensual. Dependendo do valor a ser defendido, um modelo democrático será escolhido e consequentemente, a revisão judicial será aderida ou não pelo teórico da democracia e também pelas diferentes sociedades.

\section{REFERÊNCIAS DAS FONTES CITADAS}

ACKERMAN, Bruce. The new separation of powers. Harvard Law Review, vol. 113, n.3. 2000. p. 634 a 725.

ARATO, Andrew. Representação, soberania popular, e accountability. Tradução de Heloísa B. de Almeida. Lua Nova, n. 55-56, 2002. p. 85 a 103.

BARBOZA, Estefânia Maria de Queiroz; KOZICKI, Katya. Judicialização da política e controle judicial de políticas públicas. Rev. direito GV vol.8 no.1 São Paulo jan./jun. 2012. p. 59-86.

DAHL, Robert. Um prefácio à teoria democrática. Tradução de Ruy Jungmann. Rio de Janeiro: Zahar, 1989.

DAHL, Robert A. Decision-making in a democracy: the Supreme Court as a national policy-maker. The Journal of Public Law, n. 6, 1957. p. 279 a 295,

DAHL, Robert. A democracia e seus críticos. Tradução de Patrícia F. Ribeiro. São Paulo: WMF Martins Fontes, 2012.

DWORKIN, Ronald. The Model of Rules, 35 U. CHI. L. REV. 14, 1967

DWORKIN, Ronald. A leitura moral e a premissa majoritária. In: O Direito da Liberdade: a leitura moral da Constituição norte-americana. Tradução de Marcelo B. Cipolla. São Paulo: Martins Fontes, 2006. p. 1 a 59.

DWORKIN, Ronald. A Virtude Soberana: a teoria e a prática da igualdade. Tradução de Jussara Simões. São Paulo: WMF Martins Fontes, 2013. p. 253 a 290.

${ }^{51}$ DWORKIN, Ronald [1996] A leitura moral e a premissa majoritária. p.52. 
NASCIMENTO, Luma Neto do. Dworking versus Waldron: os prós e os contras da revisão judicial. Revista Eletrônica Direito e Política, Programa de Pós-Graduação Stricto Sensu em Ciência Jurídica da UNIVALI, Itajaí, v.11, n.3, 30 quadrimestre de 2016. Disponível em: www.univali.br/direitoepolitica - ISSN 1980-7791

GAMA NETO, Ricardo Borges. Minimalismo schumpeteriano, teoria econômica da democracia e escolha racional. Rev. Sociol. Polít., Curitiba, v. 19, n. 38, fev. 2011. p. 27-42.

HART, Herbert L.A. O Conceito de Direito. 4 ed. Tradução de A. Ribeiro Mendes. Lisboa: Fundação Caloustre Gulbenkian, 2005.

LIJPHART, Arend. Modelos de democracia: desempenho e padrões de governo em 36 países. Rio de Janeiro, Ed. Civilização Brasileira, 2003.

LIJPHART, Arendt. Constitutional choices for new democracies. Journal of Democracy, vol. 2, n. 1, winter 1991. p. 72 a 84.

LIJPHART, Arendt. Constitutional design for divided societies. In: Thinking about Democracy: power sharing and majority rule in theory and practice. London and NY: Routledge, 2008. p. 75 a 88.

MADISON, J. The federalist papers by Alexander Hamilton, James Madison and John Jay. Nova York, Bantam Books. 1982. p. 337.

MAINWARING, Scott; BRINKS, Daniel; e PÉREZ-LIÑÁN, Aníbal. "Classificando Regimes Políticos na América Latina" in Dados, vol. 44, no. 4, p. 645-687, 2001.

MELO, Marcus. O viés majoritário na política comparada: responsabilização, desenho institucional e qualidade da democracia. Revista Brasileira de Ciências Sociais, vol. 22, n. 63, fevereiro de 2007. p. 11 a 29.

O'DONNELL, Guillermo. Why the rule of law matters in Diamond, Larry and Leonardo Morlino (eds.). Assessing the Quality of Democracy. Baltimore: The Johns Hopkins University Press, 2005. p 3-17.

PRZEWORSKI, Adam. Minimalist conception of democracy: a defense in Shapiro, Ian and Casiano Hacker-Cordón (eds.) Democracy's value. Cambridge: Cambridge University Press.,1999. p. 21-55.

SCHUMPETER, Joseph A. Capitalismo, Socialismo e Democracia. Tradução de Ruy Jungmann. Rio de Janeiro: Fundo de Cultura, 1961.

TOCQUEVILLE, Alexis de. A Democracia na América. Tradução de Francisco Weffort. São Paulo: Abril S. A. Cultural, 1985.

WALDRON, Jeremy. The core of the case against judicial review, Yale Law Journal, n. 115, 2006. p. 1346 a 1406.

Submetido em: junho/2016

Aprovado em: setembro/2016 